\title{
UM ESTUDO SOBRE AS PRÁTICAS PEDAGÓGICAS: ORIENTAÇÕES E DECISÕES EM SALA DE AULA
}

\author{
A STUDY ON PEDAGOGICAL PRACTICES: \\ CLASSROOM GUIDELINES AND DECISIONS
}

\author{
Maria de Fátima Barbosa Abdalla ${ }^{1}$
}

\begin{abstract}
Resumo
Este texto tem como objetivos identificar e analisar as representações sociais dos professores dos anos finais do ensino fundamental de uma escola da rede municipal sobre o que os orientam em suas tomadas de decisão durante suas práticas pedagógicas. Parte-se do pressuposto de que essas representações passam, especialmente, pelos conhecimentos didáticos que os professores possuem e expressam em relação à prática pedagógica, e que traduzem os conteúdos de seus pensamentos e de suas decisões interativas frente às situações didáticas. Trata-se de um estudo com base na teoria das representações sociais (MOSCOVICI, 2012), e que assume uma abordagem qualitativa de pesquisa, utilizando-se de questionário e entrevistas, cujos dados sinalizam para duas dimensões de análise e seus respectivos resultados sobre os conhecimentos didáticos em construção: $1^{\text {a }}$ Orientações elou lógicas na construção de conhecimentos didáticos: direcionando orientações teóricas, sociais, pessoais e/ou da experiência dos professores e para as orientações situacionais; $2^{\mathrm{a}}$ Decisões e pensamentos interativos em sala de aula: demarcando decisões de rotina, imediatas e/ou reflexivas, que orientam a construção de conhecimentos didáticos. Por fim, espera-se que os elementos aqui introduzidos em torno das orientações e decisões dos professores a respeito de como pensam e compreendem o processo de ensino e constroem os conhecimentos didáticos possam contribuir para se repensar os processos de formação, as práticas pedagógicas e a aprendizagem profissional.
\end{abstract}

Palavras-chave: Práticas pedagógicas; conhecimentos didáticos; orientações e decisões em sala de aula; representações sociais; anos finais do ensino fundamental.

\begin{abstract}
This text aims to identify and analyze the social representations of teachers of the final years of elementary school in a municipal school about what guides them in their decision-making process in their pedagogical practices. It is assumed that these representations go through, in particular, the didactic knowledge that teachers have and express regarding the pedagogical practice, and that they translate the contents of their thoughts and interactive decisions in the face of the didactic situations. This study is based on the theory of social representations
\end{abstract}

\footnotetext{
${ }^{1}$ Doutora em Educação; Universidade Católica de Santos, Santos/SP, Brasil, e-mail: mfabdalla@uol.com.br.
} 


\section{OO DEVIR EDUCAÇÃO}

ISSN: 2526-849X

(MOSCOVICI, 2012) and uses a qualitative research approach, applying questionnaires and interviews, whose data point to two dimensions of analysis and their respective results on the didactic knowledge in construction: 1st Guidelines and/or logic in the construction of didactic knowledge: Directing theoretical, social, and personal guidelines and/or guidelines from the teachers' experience and for situational guidelines; 2nd Decisions and interactive thoughts in the classroom: Demarcating routine, immediate and/or reflexive decisions that guide the construction of didactic knowledge. Finally, it is hoped that the elements introduced here with regard to the teachers' guidelines and decisions concerning how they think about and understand the teaching process and build didactic knowledge can contribute to rethinking training processes, pedagogical practices, and professional learning.

Keywords: Pedagogical practices; didactic knowledge; classroom guidelines and decisions; social representations; final years of elementary school.

\section{Introdução}

A luta das ideias, qualquer que seja sua forma, se não resolve sempre o que se propõe, responde necessariamente a um ideal de verdade do qual podemos algumas vezes nos afastar, mas nunca nos separar. (MOSCOVICI, 2012, p. 426)

O pensamento de Moscovici (2012), registrado na epígrafe inicial deste texto, instiganos a refletir sobre a importância de se lutar por nossas ideias, porque, sem dúvida, elas correspondem a um "ideal de verdade do qual podemos algumas vezes nos afastar, mas nunca nos separar" (p. 436). O que nos leva, também, a pensar na necessidade, já indicada por André (2013, p. 16), de se "ouvir os professores para conhecer o que dizem, pensam, sentem e fazem", principalmente, continua a autora, "se o que se pretende é descobrir, com eles, quais os caminhos mais efetivos para alcançar um ensino de qualidade que se reverta numa aprendizagem significativa para todos os alunos".

Diante dessa perspectiva e considerando que esta é uma luta que vale a pena enfrentar, este texto assume como objetivos identificar e analisar as representações sociais dos professores dos anos finais do ensino fundamental de uma escola da rede municipal sobre o que os orientam em suas tomadas de decisão durante as práticas pedagógicas. A intenção maior é contribuir com a formação e a aprendizagem da docência, para que seja possível ressignificar as práticas pedagógicas para professores e alunos.

Neste sentido centramos o foco nos anos finais do ensino fundamental ${ }^{2}$, pois consideramos que este é um dos grandes desafios, principalmente, porque, de acordo com a

\footnotetext{
${ }^{2}$ A Lei de Diretrizes e Bases da Educação Nacional/LDB 9.394/96 (BRASIL, 1996) estabelece que a Educação escolar se compõe da Educação Básica e da Educação Superior, e que esse Ensino Fundamental é uma das etapas
} 


\section{OO DEVIR EDUCAÇÃO}

ISSN: 2526-849X

pesquisa realizada por Davis et al. (2012), junto a Fundação Victor Civita e Fundação Carlos Chagas (FCC), intitulada "Anos Finais do Ensino Fundamental: aproximando-se da configuração atual”, há pouquíssimos estudos que “[...] tratam sobre essa fase de ensino, embora exista farta literatura sobre a criança que inicia o processo escolar e o adolescente que está em vias de concluí-lo, teórica e idealmente aquele que tem entre 15 e 17 anos” (p. 104). Um outro alerta dessa pesquisa é que "há um abismo entre pesquisadores que focam as questões pedagógicas sem incluir a discussão sobre juventude e estudiosos que pensam nos jovens, mas não nutrem das discussões provenientes das teorias pedagógicas [...]” (p. 104). Com isso, afirmam as autoras, há necessidade de que se desenvolvam "experiências que promovam a observação, a experimentação, o estabelecimento de relações entre fatos e acontecimentos", para que os alunos possam atribuir "significado e importância à passagem pela escola" (p. 115).

Além disso, há novas exigências/dificuldades que se impõem à Escola, como a diversidade do alunado, em função da própria massificação "democrática” devido à ampliação das vagas, implicando, também, a existência de novas culturas, hábitos e valores na mesma escola. É importante destacar, também, que essa pluralidade de perfis do alunado tem trazido não só novas questões para o espaço escolar, como destacam Gonçalves e Silva (2001), mas problemas de toda a ordem, especialmente, para o professor.

Gatti, Barretto e André (2011, p.137) mostram, ainda, um pouco dessa complexidade atual do professor e de suas práticas, ao revelarem, por exemplo, a necessidade dos professores não só compreenderem o "domínio de conhecimentos disciplinares" e as diferentes "metodologias de ensino", como também o "desenvolvimento cognitivo, afetivo e social das crianças e jovens" e a "capacidade de lidar com diferenças (por exemplo, a heterogeneidade dos alunos quanto a estágios de desenvolvimento, vínculos familiares, religiosos, condições econômicas etc.)". E tal complexidade ganha contornos específicos, pois o docente, em especial, dos anos finais do ensino fundamental: a) apresenta uma formação difusa; b) tem uma deficiência quanto aos conhecimentos pedagógicos no tratamento dos conteúdos desenvolvidos; c) assume uma jornada diversificada, ou seja, trabalha em mais de uma escola; d) não consegue articular um projeto pedagógico comum, e, em geral, não participa de um trabalho coletivo, apesar dos horários especiais e das exigências legais demandarem uma articulação coletiva, como indicam os art. 12 a 14 da LDB 9.394/96 (BRASIL, 1996).

da Educação Básica (Infantil, Fundamental e Médio), não havendo desagregação do Fundamental para fins de concepção e organização do ensino.

Devir Educação, Lavras, vol.4, n.1, p.7-25 jan./jun., 2020. 


\section{OO DEVIR EDUCAÇÃO}

ISSN: 2526-849X

Aliado a tudo isso, existem outros problemas a serem enfrentados pelos professores, tais como: o alargamento de suas responsabilidades; os diferenciados contextos multiculturais a que estão submetidos; as alterações ocorridas na estrutura familiar; a expansão de suas funções no âmbito da escola e da sala de aula; a influência das tecnologias de informação e comunicação; a burocratização e intensificação do trabalho docente; a avaliação dos resultados e a prestação de contas a que eles estão submetidos; e questões relacionadas ao mal-estar docente. O que torna a profissão do professor extremamente complexa e cada vez mais precarizada, principalmente, frente ao cenário de mudanças que vivenciamos, conforme apontam, também, vários autores. Dentre eles, mencionamos: Hargreaves (1998), Benavente (1999), Cavaco (1999), Esteve (1999a, 1999b), García (1999), Imbernón (2000), Estrela (2001). Flores (2003), Caetano (2004), Abdalla (2006, 2015, 2017), Melo e Augusto (2006), Formosinho (2009), Forte e Flores (2012), Gatti $(2013,2017)$ e Nóvoa (2017).

$\mathrm{E}$, diante desse cenário, é preciso que o professor assuma um olhar psicossocial para a educação, como afirmam Abdalla e Villas Bôas (2018, p. 37), no entendimento de que se trata de uma prática social, que precisa ter uma relação necessária com a mudança social, para o enfrentamento e superação de "[...] tensões e conflitos, relações de força e de sentido", que acontecem nos espaços da Escola, e, sobretudo, em suas salas de aula.

Tendo em vista os aspectos assinalados, investigar sobre as representações sociais de um grupo de professores dos anos finais do ensino fundamental a respeito do que pensam e compreendem, quando estão em sala de aula e em processo de ensino, tem sido o objetivo da pesquisa maior, que integra o Centro Internacional de Estudos em Representações Sociais e Subjetividade em Educação/CIERS-ed/FCC/Cátedra UNESCO sobre Profissionalização Docente.

Parte-se, aqui, do pressuposto de que essas representações passam, especialmente, pelos conhecimentos didáticos que os professores possuem e expressam em relação à prática de ensino. Conhecimentos estes, que, conforme Roldão (2017, p. 1143), são considerados como nucleares "[...] à ação de ensinar, entendida como intencionalidade estratégia de gerar e avaliar aprendizagens pretendidas”. Segundo a autora, o conhecimento didático também se aproxima da expressão, usada por Shulman, denominada de "saber como ensinar". E, neste sentido, para Roldão (2017, p. 1144), o conhecimento didático é tratado "[...] como o núcleo central do conhecimento profissional docente, ancorado e contextualizado por todos os restantes componentes, identificador e sustentáculo da distinção profissional que nos torna professores" (grifos da autora).

Devir Educação, Lavras, vol.4, n.1, p.7-25 jan./jun., 2020. 


\section{OO DEVIR EDUCAÇÃO}

ISSN: 2526-849X

Para nós, o conhecimento didático do professor também traduz o conteúdo de seu pensamento e de sua decisão interativa frente à situação didática. Para Altet (2000), são conteúdos de pensamentos aqueles que se concretizam por meio de: objetivos, conteúdos da matéria a ser ensinada, atividades, materiais pedagógicos, métodos e estratégias, táticas, dificuldades e ajustamentos dos alunos, processos de aprendizagem, usos do tempo, sentimentos, fantasias, entre outros aspectos.

Frente a essas questões, o trabalho se justifica na medida em que pode contribuir para colocar em discussão determinadas representações dos professores sobre o seu fazer docente. E, nesta perspectiva, a pesquisa tem por base a Teoria das Representações Sociais/TRS, de Moscovici (2005, 2012), assim como outros autores que tratam da formação e profissionalização docente, em especial, da didática, das práticas docentes e das representações sociais que as fundamentam (VERMERSH, 1977; ALTET, 2000; RUBALCAVA, 2000; SHULMAN, 2005; ABDALLA, 2006; 2015; 2017; CAMIILLONI, 2007; FARIA, 2015; LIBÂNEO, 2015; MARIN, 2015; PIMENTA, 2015, CRUZ, 2017; GATTI, 2017; ROLDÃO, 2017).

Considerando esses aspectos, o texto apresenta, na primeira seção, um quadro sintético sobre alguns elementos da TRS (MOSCOVICI, 2005, 2012), assim como de outras abordagens teóricas (VERMESCH. 1977; SHULMAN, 2005; ALTET, 2000; RUBALCAVA, 2000), para compreender a análise das práticas pedagógicas com o foco no que os professores pensam e compreendem quando ensinam. Na seção seguinte, serão abordados o contexto da pesquisa, os sujeitos e os procedimentos metodológicos. E, na terceira seção, serão analisados e discutidos os resultados da pesquisa. Por fim, espera-se que os elementos aqui introduzidos em torno do que orientam e constroem os conhecimentos didáticos dos professores, em questão, possam contribuir para se repensar os processos de formação e de aprendizagem profissional na condução de práticas pedagógicas mais significativas.

\section{Alinhavando algumas ideias a partir da TRS e de outras abordagens teóricas}

Consideramos importante retomar a TRS, de Moscovici (2012), para entender as razões e/ou as crenças que levam os professores a configurarem representações/imagens sobre o que pensam e compreendem quando ensinam; ou seja, entender como eles constroem os seus conhecimentos didáticos na orientação de suas práticas pedagógicas.

Devir Educação, Lavras, vol.4, n.1, p.7-25 jan./jun., 2020. 


\section{OO DEVIR EDUCAÇÃO}

ISSN: 2526-849X

Nessa direção, é preciso compreender a noção de representações sociais, que, conforme destaca Moscovici (2012, p. 344), “[...] são ferramentas mentais, operando na própria existência, conformando o contexto em que os fenômenos estão radicados". Além disso, consideramos, também, as palavras do autor, quando afirma que: "Representar uma coisa, um estado, não é só desdobrá-lo, repeti-lo ou reproduzi-lo, é reconstituí-lo, retocá-lo, modificar-lhe o texto" (p. 54).

Ainda, é importante tratar, neste texto, que, para Moscovici (2012), há dois processos que fundamentam a representação social: a objetivação e a ancoragem. Moscovici (2012, p. 100) destaca que: “[...] a objetivação permite tornar real um esquema conceitual e substituir uma imagem por sua contrapartida material, resultado que tem primeiramente um alcance cognitivo". Já a ancoragem refere-se à assimilação das imagens criadas pela objetivação, ou seja, "[...] é um processo que transforma algo estranho e perturbador, que nos intriga, em nosso sistema particular de categorias e o compara com um paradigma de uma categoria que nós pensamos ser apropriada" (p. 61). É como se fosse "[...] ancorar um bote perdido em um dos boxes (pontos sinalizadores) de nosso espaço social” (p. 61).

A partir desses elementos da TRS, levamos em conta, também, o que Shulman (2005, p. 11) considera como o "conhecimento didático geral" e "conhecimento didático do conteúdo". Conforme o autor: a) conhecimento didático geral: são "[...] aqueles princípios e estratégias gerais de manejo e organização de classe, que transcendem o âmbito do assunto" (p. 11); e b) conhecimento didático do conteúdo: é uma espécie de “[...] amálgama entre a matéria e a pedagogia que constitui uma esfera exclusiva dos professores, sua própria forma especial de compreensão profissional” (p. 11) (tradução livre).

Neste sentido, Shulman (2005) afirma que o conhecimento didático do conteúdo adquire particular interesse, pois o mesmo: a) identifica os "corpos de conhecimentos distintivos para o ensino"; e b) tece relação entre a "matéria" e a "didática", ao se pretender compreender "[...] como determinados temas e problemas se organizam, se representam e se adaptam aos diversos interesses e capacidades dos alunos, e se expõem para seu ensino” (p. 11) (tradução livre).

Nesse estudo, mesmo tratando das representações dos professores sobre a construção de seus conhecimentos didáticos, o que pretendemos compreender é a respeito do conhecimento didático do conteúdo. No caso, o que pensam e como fazem os professores quando ensinam e constroem suas práticas pedagógicas.

Também, Vermesch (1977) contribui com este trabalho, ao analisar os discursos dos professores a partir de três lógicas: $1^{\circ}$ a lógica da matéria - que diz respeito às “[...] definições 


\section{OO DEVIR EDUCAÇÃO}

ISSN: 2526-849X

e relações entre conceitos da matéria a ser ensinada" (p. 2); $2^{\circ}$ a lógica da ação - que define "a sequência de operações necessárias para resolver uma classe de problemas" (p. 2); e $3^{\circ}$ a lógica pedagógica - que "trata de ordenar a progressão pedagógica" (p. 2) (tradução livre). Essas lógicas, segundo o autor, antecipam as situações pedagógicas. Para nós, essas lógicas vão delineando e dando concretude às práticas pedagógicas e às representações sobre elas.

Ainda a respeito das "lógicas", Moscovici (2005, p. 334) afirma que há sempre uma “unidade lógica ou cognitiva de nossa vida mental”, considerando, neste sentido, a importância das normas, contextos e fins. Pois, segundo o autor, são estes elementos que guiam as práticas, aqui entendidas, também, como práticas pedagógicas, fazendo circular diferentes representações que as guiam.

Há mais três aspectos, que nos ajudam a desvendar o que pensam e/ou compreendem os professores, quando tratam do ensino e da organização das práticas pedagógicas: $1^{\circ}$ as orientações, que envolvem o conhecimento do professor, e que, segundo Rubalcava (2000), podem ser: situacional, teórica, pessoal, social e aquelas que partem da própria experiência, que, na análise, denominaremos, também, como "orientação pessoal"; $2^{\circ}$ a natureza das decisões interativas dos professores em aula, que, segundo Altet (2000), classificam-se em: decisões de rotina, decisões imediatas e decisões reflexivas; e $3^{\circ}$ os conteúdos dos pensamentos interativos dos professores (ALTET, 2000). Neste texto, os dois últimos aspectos serão tratados conjuntamente, ou seja, em uma única dimensão de análise.

Frente à diversidade de perspectivas e enfoques dos diferentes estudos, este texto abordará o que pensam e compreendem os professores sobre a construção de seus conhecimentos didáticos, identificando as orientações que assumem para construí-los, suas decisões e pensamentos interativos no desenvolvimento das práticas pedagógicas. Para nós, esses aspectos contribuem, ainda, para olhar, mais de perto, as representações dos professores sobre o seu ofício de ser e estar na profissão docente (ABDALLA, 2006, 2015, 2017).

\section{Do contexto da pesquisa e dos procedimentos metodológicos}

A escola selecionada é dos anos finais do ensino fundamental e funciona em uma região periférica da cidade de Santos/SP. Tem 115 professores e atende a 967 alunos. Os sujeitos da pesquisa são 20 professores, que lecionam as seguintes disciplinas: História (5), Português (5), Matemática (4), Biologia (2), Geografia (2), Artes (1) e Educação Física (1). Tais professores atuam nos três turnos, e possuem, de acordo com o questionário aplicado, as seguintes 


\section{OO DEVIR EDUCAÇÃO}

ISSN: 2526-849X

características: a) 5 homens (30\%) e 15 mulheres (70\%); b) $20 \%$ têm 41 anos e $80 \%$ apresentam idade de 31 a 40 anos; c) 50\% consideram-se brancos, 40\% negros e 10\% pardos; d) 55\% são solteiros; $40 \%$ casados e 5\% separados; e) $48 \%$ não têm filhos; $42 \%$ possuem somente um filho; e $10 \%$ têm dois filhos.

Quanto aos procedimentos metodológicos, a pesquisa se desenvolveu em duas etapas no âmbito de uma abordagem qualitativa de pesquisa (BOGDAN; BIKLEN, 1994). Na primeira, foi aplicado um Questionário de Perfil para 20 professores, contendo 28 questões fechadas, e duas questões abertas, conforme seguem: "O que os orienta, quando propõe e/ou desenvolve uma prática pedagógica? E quando você está em sala de aula, que tipo de decisão toma e que considera a mais difícil ou desafiadora? (Para isso, conte um caso)". Na segunda etapa, foram realizadas semiestruturadas com 5 professores ( 3 mulheres e 2 homens), que participaram da primeira etapa, e os resultados aqui tratados também dizem respeito às duas questões anteriores.

O que estamos querendo examinar, como mencionado, é aquilo que Shulman (2005, p. 11) denomina como "conhecimento didático do conteúdo". Ou seja, compreender "[...] como determinados temas e problemas se organizam, se representam e se adaptam aos diversos interesses e capacidades dos alunos, e se expõem para seu ensino" (tradução livre), de modo a dar sentido/significado às práticas pedagógicas desenvolvidas.

Os instrumentos utilizados tiveram como eixos de análise: a trajetória de formação, os saberes da docência, as decisões pedagógicas, o planejamento, as estratégias didáticas, a avaliação e os pensamentos em sala de aula, descritos pelos professores em suas narrativas.

Após a organização e o tratamento dos dados, foi realizada a análise de conteúdo (BARDIN, 2007), que, juntamente com a TRS (MOSCOVICI, 2012) e outros referenciais já mencionados, contribuíram para identificar, pelo menos, duas dimensões de análise, que serão apresentadas na seção seguinte.

\section{Resultados e discussões}

Tendo em vista a análise de conteúdo (BARDIN, 2007) e a TRS (MOSCOVICI, 2005, 2012), as representações sociais dos professores foram ancoradas, como diria Moscovici (2012), em duas dimensões de análise, registradas a seguir. Estas dimensões mostram, ainda que parcialmente, os resultados da pesquisa e as discussões a este respeito. 


\section{OO DEVIR EDUCAÇÃO}

ISSN: 2526-849X

\section{- Orientações e lógicas na construção de conhecimentos didáticos ( $1^{\mathrm{a}}$ dimensão)}

Segundo Moscovici (2005, p. 334), como vimos, há sempre uma "unidade lógica ou cognitiva de nossa vida mental", que regula "[...] a escolha que fazemos de uma forma de pensamento, com preferência a outra" (p. 334). Nesta direção, há, conforme o autor, três elementos que nos condicionam, de alguma forma, para esta escolha e tomada de decisão, que são: o contexto, as normas e os fins (p. 334). E isso significa que as orientações dão um rumo ao que queremos.

Ao perguntar, então, para os professores o que os orientam, quando propõem e/ou desenvolvem uma prática pedagógica? Foram essas as suas respostas:

Primeiro, penso em meus alunos; ou seja, que tipos de atividades darão a eles condições de aprendizagem. Depois, procuro, logo, inventar alguma estratégia didática que possa convencê-los a participar da aula e ter interesse na matéria que pretendo ensinar. (Suj. 6, Profa. Português, Questionário)

Penso em três coisas: o objetivo, que foi delineado no meu planejamento (para onde quero chegar com os alunos?); o conteúdo (o que quero ensinar?); e as atividades a serem desenvolvidas (como pretendo que eles aprendam?). (Suj. 16, Profa. Biologia, Questionário)

Ultimamente, tenho pensado no tempo que tenho para organizar a minha aula; depois, as condições de aprendizagem dos alunos; os tipos de atividades que melhor se adequam ao conteúdo que pretendo desenvolver. Como você sabe, nunca dá tempo para nada. (Suj. 17, Profa. Geografia, Entrevista)

Se tomarmos Moscovici (2012), para a análise das representações dessas professoras, observamos que elas refletem, em suas falas, sobre as finalidades de seu ofício de ensinar, que é fazer com que o outro aprenda a relação com o conhecimento. Também, não se esquecem das normas, que podemos, aqui, traduzir como: conteúdos, regras, estratégias, condições de ensino e aprendizagem. E, por fim, não menosprezam a questão do contexto, ou seja, do tempo e do espaço de sala de aula.

Por outro lado, percebemos que este processo de orientação toma forma desde o planejamento, e tem a ver, conforme Rubalcava (2000), com: uma orientação teórica, o que escolher do conteúdo a ensinar sob a perspectiva de referenciais teóricos; uma orientação social, que retrata uma adequação à turma, à direção e/ou à Escola como um todo; e uma orientação pessoal, da própria experiência enquanto professor. São estes os registros nesta perspectiva: 


\section{OO DEVIR EDUCAÇÃO}

ISSN: 2526-849X

Quando proponho uma aula, ou melhor, quando planejo uma situação de ensino, penso, primeiro, no conteúdo que vou trabalhar. Mas, é lógico, que não deixo de pensar naquelas minhas turminhas, pois é para eles que ensino. Depois, fico pensando qual seria o melhor modo de trabalho. (Suj. 1, Profa. História, Questionário)

Sou professora de Artes. Adoro o que faço, e me oriento pelo planejamento, pelos conteúdos que preciso desenvolver e como trabalhar com eles. Mas fico sempre pensando na escola, como um todo. Por quê? Porque a direção acha que faço muito barulho. Já expliquei a ela que tenho poucas aulas para cada turma, e isso me dificulta o trabalho. Agora, tenho que pensar, também, nas "normas" da Escola? Mas isso depende da direção, porque, na outra escola, não tenho este problema, pois sou livre para trabalhar com meus alunos e eles gostam muito do que faço. (Suj. 19, Profa. Artes, Entrevista)

A fala da Professora de História (Suj. 1) reforça a importância do conteúdo; entretanto, não deixa de lado questões em torno do modo em que desenvolverá este conteúdo, tendo em vista os seus alunos. Já a última fala referente à Professora de Artes (Suj. 19) nos faz pensar naquilo que Rubalcava (2000, p. 272) considera como “orientação situacional”, em que "o professor se serve de seu conhecimento para destacar uma preocupação e reconhecimento explícito sobre o que está acontecendo em uma situação específica a partir de sua observação, comparação ou ensaios diversos" (tradução livre). Neste sentido, é quando o professor enfrenta uma situação pedagógica um pouco mais problemática e que precisa usar outras estratégias didáticas para desenvolver o seu conteúdo ou lidar com questões contextuais mais amplas. Tais aspectos retratam, também, o que nos lembra Shulman (2005), quando reflete sobre o "conhecimento didático do conteúdo".

No exemplo, a seguir, observamos que o Professor de História constrói diferentes conhecimentos didáticos ou formas de trabalhar didaticamente com o conteúdo, conforme Shulman (2005), para dar conta do desenvolvimento do conteúdo nas realidades da $6^{\mathrm{a}} \mathrm{C}$ e da $6^{\mathrm{a}}$ B:

Para uma turma, por exemplo, para a $6^{\mathrm{a}} \mathrm{C}$, não tenho condições de fazer trabalhos em grupo, porque eles são muito indisciplinados e parecem que não querem nada com nada. E isso atrapalha aqueles que querem aprender. Então, sei que, para eles, no máximo, trabalho com duplas, escolhidas por mim, e com determinados conteúdos, porque sei, mais ou menos, como eles se dão. De qualquer forma, há uma turma, a $6^{\mathrm{a}}$ série $\mathrm{B}$, que é muito interessada em tudo que explico. Brinco até de teatro com eles. É uma maravilha! (Suj. 5, Prof. História, Entrevista)

Também, poderíamos compreender que a construção deste conhecimento didático do conteúdo passa, diria Vermesch (1977), por três lógicas diferentes. Observamos que tanto os 


\section{OO DEVIR EDUCAÇÃO}

ISSN: 2526-849X

professores de História (Sujs. 1 e 5), quanto a professora de Artes (Suj. 19), assumem lógicas da matéria, da ação e pedagógicas; ou seja, o que, o como e para quê desenvolver o conteúdo de História e de Artes, identificando operações necessárias para a aprendizagem. Todavia, é a lógica da situação, diria Altet (2000), que está, de certa forma, regulando as diferentes práticas pedagógicas vivenciadas por esses e outros professores. Lógica esta que, por exemplo, está "amarrada", diria Moscovici (2005), em questões de "normas" regidas pela Escola, no caso da Professora de Artes (Suj. 19), e/ou de "contexto", especialmente, com o Professor de História (Suj. 5) e suas diferentes turmas $\left(6^{\mathrm{a}} \mathrm{B}\right.$ e $\left.6^{\mathrm{a}} \mathrm{C}\right)$.

É preciso assinalar que as representações docentes, aqui, também, podem ser imbuídas, como afirma Camilloni (2007, p. 45), de "[...] crenças, que, por certo, estão sustentando as disposições" (grifo da autora). Disposições, que são "[...] entendidas como conjuntos de ações que podem ser observadas" (tradução livre) (p. 45). O que nos leva a pensar, a seguir, nas decisões e pensamentos interativos que os professores têm em sala de aula e que, também, orientam seus conhecimentos didáticos, ou melhor, seus "conhecimentos didáticos de conteúdo" (SHULMAN, 2005) e conduzem suas práticas pedagógicas.

\section{- Decisões e pensamentos interativos em sala de aula (2 $2^{\mathrm{a}}$ dimensão)}

Do ponto de vista da TRS (MOSCOVICI, 2012, p. 231), observamos, durante as entrevistas realizadas, que há "[...] de um lado, relações operatórias comuns e, de outro, relações normativas que controlam, verificam, dirigem as primeiras". Tais relações conduzem os pensamentos interativos e suas decisões, e, nas quais, “[...] os interlocutores exprimem e forjam suas opiniões considerando a dos outros" (p. 230). Trata-se, continua o autor, “[...] de um pensamento que se desenvolve frequentemente durante a interação face a face" (p. 230).

Para além dessas questões, enfatizadas por Moscovici (2012) quanto ao procedimento das entrevistas, recordamo-nos, também, de Altet (2000, p. 115-116), quando classifica as decisões interativas dos professores em aula em: decisões de rotina, decisões imediatas e decisões reflexivas.

Para Altet (2000, p. 115), as decisões de rotina são aquelas que se constituem em "um repertório de condutas interiorizadas, estabelecidas, automáticas"; as decisões imediatas são as que demandam uma "compreensão imediata da situação" (p. 116), ou seja, são aquelas mais intuitivas e rápidas; e as decisões reflexivas são as que "reclamam reflexão e avaliação" (p. 116). As decisões reflexivas têm, segundo a autora, uma "origem dupla", porque trata: a) da 


\section{OO DEVIR EDUCAÇÃO}

ISSN: 2526-849X

utilização de "esquemas previstos" ou um "retomar de decisões pré-ativas (esquemas informatizados ou operacionais)" (p. 116); e b) de "improvisações" ou ao que ela denomina como "improvisação preparada", que é aquela que prevê "um inventário de estratégias e táticas possíveis para melhor se adaptar aos alunos e às interações" (p. 116).

Além disso, Altet (2000) nos ajuda a pensar melhor, quando nos explica que as decisões interativas podem assumir duas formas: a) adaptação, quando se ajusta aos alunos e/ou ao contexto; b) não ajustamento à situação e funcionamento implícito do professor, quando os professores, no nosso caso, não se ajustam às situações e procuram resolvê-las, primeiro, no nível dos pensamentos interativos. De certa forma, procuramos observar, nas falas dos professores, que tipo de pensamentos e decisões interativas tomam e se há "adaptação" ou "não ajustamento" quanto às decisões de sala de aula.

É preciso destacar, ainda, que Altet (2000, p. 116), baseada em pesquisas, elabora uma lista de pensamentos interativos dos professores, quando da tomada de decisões, constituída por: objetivos; conteúdos; atividades; materiais; métodos e estratégias; táticas; alunos (dificuldades percebidas, ajustamentos); processo de aprendizagem; tempo; sentimentos e fantasias; dentre outros elementos.

Tendo em vista as considerações moscovicianas e as proposições de Altet (2000) quanto às decisões e pensamentos interativos, perguntamos aos nossos sujeitos: "E quando você está em sala de aula, que tipo de decisão toma e que considera a mais difícil ou desafiadora? (Para isso, conte um caso)". E são essas as suas falas:

São muitos os problemas a serem enfrentados com aquela $7^{\text {a }}$ série C. Como é difícil trabalhar com eles! Outro dia, fui trabalhar com um texto sobre a questão dos argumentos e como defender ideias opostas. Daí, pensei em uma situação de debate: faríamos uma espécie de jurado, com advogados, de um lado, e promotores do outro, defendendo as ideias e debatendo-as. Mas foi tanto barulho, que perdi a paciência! Dei um grito! E aquilo foi o fim para mim. Mandei todos eles para os seus devidos lugares, e dei uma avaliação, em que teriam que construir um texto de defesa e um contra. Me senti muito mal. Tudo o que aprendi de didática foi para o fundo do poço. A minha vontade era de desistir de tudo... (Suj. 9, Profa. de Português, Entrevista)

Você me pergunta sobre como resolvo ou não uma situação pedagógica mais difícil e como construo um conhecimento didático que me dê suporte para enfrentar os problemas com o conhecimento que quero passar aos meus alunos. Posso lhes dizer que não é fácil, mas acho que minha experiência me ajuda muito. Às vezes, "tiro de letra", mas em outras, também sofro, como no primeiro dia, em que comecei a dar aulas. Acho que uma boa saída é tentar "quebrar" as rotinas, inovar nas estratégias. Mas não consigo entusiasmo para isso, quando encontro problemas com as atitudes de alguns alunos. Isso me

Devir Educação, Lavras, vol.4, n.1, p.7-25 jan./jun., 2020. 


\section{OO DEVIR EDUCAÇÃO}

ISSN: 2526-849X

tira do sério! Conto um caso: no outro dia, fui chamar a atenção de um menino, da $8^{a}$ série, que gozava dos outros a todo momento. Ele se acha o "bom" na matemática, e isso me incomoda, porque não deixa os colegas aprenderem. Ele chama a todos de "babaca", e não tinha dado atenção a isto, até que vi que ele precisava de uma chamada. Mas não queria constrangê-lo, então falei a ele de um "cara chato", que vivia perturbando seus colegas. Ele olhou para mim e falou: Sou eu, professor? E respondi: O que acha? Mas falei, também, que ele era bastante inteligente para tomar cuidado com as palavras e procurar ajudar os outros, pois ele se sairia bem melhor não só na minha aula... Logo depois, pedi a ele para ser o "Professor da vez", em um trocadilho com a "Bola da vez", e dar aulas para os colegas. Ele adorou ser o professor, e parece que tudo ficou bem. Mas digo a você, que é a experiência que fui ganhando ao longo de minha vida, que me fez tomar esta atitude. Nesta hora, me dei bem! (Suj. 13, Prof. de Matemática, Entrevista)

Analisando as duas narrativas anteriores, podemos verificar que os professores ora retomam as decisões, ora improvisam, e retiram de suas "bagagens didáticas" algumas saídas; ora isso não acontece e se frustram. Suas decisões foram interativas, mas, nos casos das situações-problema, foram, às vezes, imediatas e outras reflexivas, quando se adaptaram ao contexto e/ou não se ajustaram às situações, desenvolvendo outras que oportunizaram melhores condições de aprendizagem para seus alunos. Exemplificando melhor: a Professora de Português (Suj. 9) acaba tomando uma atitude brusca, ou seja, uma decisão imediata, porque, como afirma Altet (2000, p. 116), "a aula não se desenrola como o previsto", e ela se "frustra"; e o Professor de Matemática (Suj. 13) usou, como diria Altet (2000, p. 116), de "uma espécie de improvisação preparada", para "melhor se adaptar aos alunos e às interações", e ele também "se deu bem".

Notamos, também, que tanto a Professora de Português, quanto o de Matemática, ao contarem, nas entrevistas, seus respectivos casos de ensino, tomam decisões reflexivas, porque refletem e avaliam sobre as situações pedagógicas que enfrentaram, e, de algum modo, revelam que se ajustaram ou não a essas situações problemáticas.

Esses exemplos mostram, conforme destaca Rubalcava (2000, p. 273), que o conhecimento didático "[...] aparece na medida em que avança o desenvolvimento da classe, porque precisamente o professor está reconhecendo o contexto". E, no caso descrito anteriormente, observamos que os professores estão reconhecendo o contexto e se reconhecendo no contexto, vivenciando situações e práticas pedagógicas como desafios a serem enfrentados, apesar ou por conta de toda a experiência que eles apresentam como professores dos anos finais do ensino fundamental. 


\section{OO DEVIR EDUCAÇÃO}

ISSN: 2526-849X

Essas decisões interativas indicam representações na ordem do contexto, das normas e dos fins, como nos ensina Moscovici (2005, p. 334), e dependem, ainda, da articulação que temos com o "contexto e também da representação que nós temos dele". E é, neste sentido, que pensar nas decisões e pensamentos interativos, que os professores tomam em sala de aula, parece-nos um caminho acertado para se estudar a construção do conhecimento didático, ou melhor, do "conhecimento didático do conteúdo" (SHULMAN, 2005). Conhecimento este que irá sedimentar práticas pedagógicas mais significativas para professores e alunos.

\section{Considerações Finais}

O estudo, ao partir das representações dos professores sobre o que pensam e como compreendem o seu fazer docente, reforça a importância de se entender os conhecimentos didáticos em construção. Conhecimentos estes que se produzem em uma forma de redes conceituais e crenças e que expressam uma relação com a prática pedagógica, traduzida em conteúdos dos pensamentos dos professores e por suas decisões interativas.

Neste sentido, a pesquisa sinaliza para duas dimensões de análise. A primeira diz respeito às orientações elou lógicas na construção de conhecimentos didáticos. O que direcionou para as orientações teóricas, quando os professores, em questão, utilizam-se dos referenciais teóricos para compreender as realidades vivenciadas; porém, não descartam o conhecimento didático, ou seja, o modo como desenvolvem os conteúdos previstos, como relacionam a teoria à prática, a matéria à didática, organizando formas de se trabalhar com o conhecimento, de organizá-lo e adaptá-lo às necessidades e interesses dos alunos. O que indicaria o conhecimento didático do conteúdo como diria Shulman (2005).

Também foi possível observar que os professores acabam se integrando às orientações sociais, estruturadas por normas, contextos e fins, ao confrontarem seus pensamentos em relação às situações didáticas desenvolvidas em sala de aula e/ou na Escola.

Por outro lado, quando os professores procuram resolver as demandas dos alunos e/ou dos diversos contextos sociais, orientam-se por suas próprias experiências; ou seja, pelas opções pessoais que consideram de maior significado para o aprendizado de seus alunos e que, de certa forma, já se associam às situações bem-sucedidas que foram vivenciadas anteriormente. Além disso, os professores também desenvolvem suas práticas pedagógicas pelas orientações situacionais, que se traduzem por conhecimentos que influenciam o professor, quando associam 


\section{OO DEVIR EDUCAÇÃO}

ISSN: 2526-849X

a teoria à prática mediante contextos desafiadores, em que, geralmente, expressam uma contradição entre a teoria e as necessidades da prática.

A segunda dimensão, que denominamos como decisões e pensamentos interativos em sala de aula, demarca decisões de rotina, imediatas e/ou reflexivas, que orientam a construção de conhecimentos didáticos. As decisões de rotina, como vimos, são aquelas tomadas quase que automaticamente, no âmbito de um repertório de atitudes interiorizadas; as decisões imediatas são aquelas que demandam de juízos instantâneos; e as reflexivas, que são as decisões mais consistentes. Ou seja, tomadas a partir de reflexões e avaliações do processo de ensino e aprendizagem, seja por meio dos esquemas operacionais e/ou de improvisações preparadas, tal como enuncia Altet (2000).

Nessa direção, analisamos os dados a partir da TRS, de Moscovici (2005, 2012), por conta de três razões centrais. A primeira, porque partimos do entendimento, junto com Moscovici (2005), de que as representações sociais são "ferramentas mentais", que operam e conformam nossos pensamentos e crenças ao contexto, em que os fenômenos se realizam. A segunda, porque apreendemos, também, que o modo como lidamos com as informações e com nossos pensamentos e decisões interativas, a partir das práticas pedagógicas vivenciadas, reforça questões em torno do contexto e das representações que temos a partir dele. E, a terceira, quando repensamos nossas escolhas e decisões, considerando os três elementos moscovicianos - o contexto, as normas e os fins -, que regulam nossas formas de pensamento. Para nós, isso esclarece algumas de nossas opções por enveredar pelo caminho das representações sociais a fim de conhecer o que os professores pensam e como constroem seus conhecimentos didáticos no desenvolvimento de suas práticas.

Por fim, ao identificar e analisar, por meio das representações docentes, as lógicas que estão por detrás das orientações, das decisões e pensamentos interativos, que dão suporte à construção dos conhecimentos didáticos, às opções estratégicas de se desenvolver ou construir conhecimentos com os alunos, esperamos ter contribuído, pelo menos, com algumas pistas. Pistas estas que possibilitem repensar o campo da didática, os processos de formação e de aprendizagem profissional na condução de práticas pedagógicas mais significativas para todos os alunos. Afinal, não é essa a nossa luta?

\section{Referências}

Devir Educação, Lavras, vol.4, n.1, p.7-25 jan./jun., 2020. 
ABDALLA, Maria de Fátima Barbosa. O senso prático de ser e estar na profissão. São Paulo: Cortez, 2006.

ABDALLA, Maria de Fátima Barbosa. Saberes da docência: definindo pistas para inovar as práticas pedagógicas. Revista de Educação da PUC-Camp., Campinas, vol. 20, n. 3, p. 215 227, set/dez, 2015. Disponível em: https://www.researchgate.net/publication/319926250. Acesso em: 29 abril 2019.

ABDALLA, Maria de Fátima Barbosa. Formação, profissionalidade e representações profissionais dos professores: concepções em jogo. Revista de Educação da PUC-Camp., Campinas, vol. 22, n. 2, p. 171-190, maio/ago. 2017. Disponível em: http://periodicos.puccampinas.edu.br/seer/index.php/reveducacao/article/view/3636/2456.

ABDALLA, Maria de Fátima Barbosa; VILLAS BÔAS, Lúcia. Um olhar psicossocial para a educação. Cadernos de Pesquisa, São Paulo, vol. 48, p. 14-41, 2018.

ALTET, Marguerite. Análise das práticas dos professores e das situações pedagógicas. Porto: Porto Editora, 2000.

ANDRÉ, Marli. Políticas de apoio aos docentes em estados e municípios brasileiros: dilemas na formação de professores. Educar em Revista. Curitiba, n. 50, p. 35-49, ou./dez. 2013. Disponível em: http://www.scielo.br/pdf/er/n50/n50a04.pdf. Acesso em: 03 maio de 2018.

BARDIN, Laurence. Análise de conteúdo. Lisboa: Edições 70, 2007.

BENAVENTE, Ana. Escola, professores e processos de mudança. $2^{\text {a }}$. ed. Lisboa: Livros Horizonte, 1999.

BOGDAN, Robert; BIKLEN, Sari K. Investigação Qualitativa em Educação. Porto: Porto Editora, 1994.

BRASIL. Lei n. 9.394, de 20 de dezembro de 1996. Estabelece as diretrizes e bases da educação nacional. Diário Oficial da União. Brasília: Casa Civil da Presidência da República, 1996. Disponível em: <http://www.planalto.gov.br/ccivil_03/Leis/L9394.htm>. Acesso em: 30 maio 2014.

CAETANO, Ana Paula. A complexidade dos processos de formação e a mudança de professores: um estudo comparativo entre situações de formação pela investigação-ação. Porto: Porto Editora, 2004.

CAMILlONI, Alicia R. W. de. Los profesores y el saber didáctico. In: CAMILLONI, A. R. W.; COLS, E.; BASABE, L.; FEENEY, S. El saber didáctico. Buenos Aires: Paidós, 2007, p. 41-60.

CAVACO, Maria Helena. Ofício do professor: o tempo e as mudanças. In: NÓVOA, A. Profissão Professor. $2^{a}$ ed. Porto: Porto Editora, 1999, p. 155-191.

CRUZ, Giseli Barreto da. Ensino de Didática e aprendizagem da docência na formação inicial de professores. Cadernos de Pesquisa, v. 47, n. 166, p. 1166-1195, out./dez. 2017. Disponível 


\section{OO DEVIR EDUCAÇÃO}

ISSN: 2526-849X

em: http://www.scielo.br/pdf/cp/v47n166/1980-5314-cp-47-166-1166.pdf. Acesso em: 04 abril 2018.

DAVIS, Claudia Leme Ferreira; TARTUCE, Gisela Lobo; NUNES, Marina Muniz Rossa; ALMEIDA, Patrícia C. Albieri; SILVA, Marina Muniz Rosa; COSTA, Beatriz Souza Dias de Olival; SOUZA, Juliana Cedro de. Anos Finais do Ensino Fundamental: aproximando-se da configuração atual. In: Estudos \& Pesquisas Educacionais, n. 3. São Paulo: Fundação Victor Civita, Fundação Carlos Chagas (FCC), nov. 2012, p. 103-193. Disponível em: https://abrilfundacaovictorcivita.files.wordpress.com/2018/04/estudos_e_pesquisas_educacio nais_vol_3.pdf. Acesso em: 12 outubro de 2016.

ESTEVE, José M. Mudanças sociais e função docente. In: NÓVOA, A. Profissão Professor. $2^{a}$. ed. Porto: Porto Editora, 1999a, p. 93-124.

ESTEVE, José M. O mal-estar docente: a sala de aula e a saúde dos professores. Bauru: Edusc, 1999 b.

ESTRELA, Maria Teresa. Questões de profissionalidade e profissionalismo docente. In: TEIXEIRA, M. (Org.). Ser Professor no limiar do século XXI. Porto: ISET, 2001, p. 113142.

FARIA, Lenilda Rego Albuquerque de. As orientações educativas contra-hegemôncias em face dos questionamentos pós-modernos. E a Didática com isso? In: MARIN, A. J.; PIMENTA, S. G. (Orgs.). Didática: teoria e pesquisa. Araraquara: Junqueira \& Marin, 2015, p. 67-97.

FLORES, Maria Assunção. Dilemas e desafios na formação de professores. In: MORAES, M. C.; PACHECO, J. A.; EVANGEliSTA, M. O. (Orgs.). Formação de Professores: perspectivas educacionais e curriculares. Porto: Porto Editora, 2003, p. 127-160.

FORMOSINHO, João (Org.). Formação de Professores: aprendizagem profissional e a acção docente. Porto: Porto Editora, 2009.

FORTE, Ana Maria; FLORES, Maria Assunção. Potenciar o desenvolvimento profissional e a colaboração docente na escola. Cadernos de Pesquisa, v. 42, n. 147, p. 900-919, set./dez. 2012. Disponível em: http://www.scielo.br/pdf/cp/v42n147/14.pdf. Acesso: 08 maio 2019.

GARCÍA, Carlos Marcelo. Formação de Professores: para uma mudança educativa. Porto: Porto Editora, 1999.

GATTI, Bernadete Angelina. Valorização da docência e avaliação do trabalho docente: o papel da avaliação participativa em um contexto institucional. In: GATTI, B. A. (Org.). O trabalho docente: avaliação, valorização, controvérsias. Campinas: Autores Associados. São Paulo: Fundação Carlos Chagas, 2013, p. 153-176.

GATTI, Bernadete Angelina. Didática e formação de professores: provocações. Cadernos de Pesquisa, v. 47, n. 166, p. 1150-1164, out./dez. 2017. Disponível em: http://www.scielo.br/pdf/cp/v47n166/1980-5314-cp-47-166-1150.pdf. Acesso em: 02 abril 2018. 
GATTI, Bernadete Angelina; BARRETO, Elba Siqueira de Sá; ANDRÉ, Marli Eliza Dalmazo de Afonso. Políticas Docentes no Brasil: um estado da arte. Brasília: UNESCO, 2011.

GONÇALVES, Luiz Alberto Oliveira; SILVA, Petronilha Beatriz Gonçalves. O jogo das diferenças: o multiculturalismo e seus contextos. $3^{\text {a }}$ ed. Belo Horizonte: Autêntica, 2001.

HARGREAVES, Andy. Os professores em tempos de mudança. Alfragide: McGraw-Hill, 1998.

IMBERNÓN, Francisco. Formação docente e profissional: formar-se para a mudança e a incerteza. São Paulo: Cortez, 2000.

LIBÂNEO, José Carlos. Antinomias na formação de professores e a busca de integração entre o conhecimento pedagógico-didático e o conhecimento disciplinar. In: MARIN, A. J.; PIMENTA, S. G. (Org.). Didática: teoria e pesquisa. Araraquara: Junqueira \& Marin, 2015, p. 39-65.

MARIN, Alda Junqueira. A didática, as práticas de ensino e alguns princípios para a pesquisa e a docência. In: MARIN, A. J.; PIMENTA, S. G. (Org.). Didática: teoria e pesquisa. Araraquara: Junqueira \& Marin, 2015, p. 17-37.

MELO, Savana D. G.; AUGUSTO, Maria Helena Oliveira Gonçalves. Reformas educacionales y precarización del trabajo docente: el caso de Minas Gerais - Brasil. In: FELDFEBER, M.; OLIVEIRA, D. A. (Orgs.). Políticas educativas y trabajo docente: nuevas regulaciones ¿Nuevos sujetos? Buenos Aires: Centro de Publicaciones Educativas y Material Didáctico, 2006, p. 281-298.

MOSCOVICI, Serge. Representações sociais: investigações em psicologia social. $3^{\text {a }}$. ed. Petrópolis: Vozes, 2005.

MOSCOVICI, Serge. A psicanálise, sua imagem e seu público. Petrópolis: Vozes, 2012.

NÓVOA. António. Firmar a posição como professor, afirmar a profissão docente. Cadernos de Pesquisa, v. 47, n. 166, p. 1106-1133, out./dez., 2017. Disponível em: http://www.scielo.br/pdf/cp/v47n166/1980-5314-cp-47-166-1106.pdf. Acesso em: 5 de abril de 2018.

PIMENTA, Selma Garrido. O protagonismo da Didática nos cursos de licenciatura: a Didática como campo disciplinar. In: MARIN, A. J.; PIMENTA, S. G. (Org.). Didática: teoria e pesquisa. Araraquara: Junqueira \& Marin, 2015, p. 81-97.

ROLDÃO, Maria do Céu. Conhecimento, Didáctica e Compromisso: o triângulo virtuoso de uma profissionalidade em risco. Cadernos de Pesquisa, v. 47, n. 166, p. 1134-1149, out./dez. 2017. Disponível em: http://www.scielo.br/pdf/cp/v47n166/1980-5314-cp-47-166-1134.pdf. Acesso em: 04 março 2018.

RUBALCAVA, Alma Elena Figueroa. Una alternativa para la evaluación de la enseñanza en educación superior desde la perspectiva de los profesores. In: BELTRÁN, M. R.; ARCEO, 
F.D.B. (Org.). Evaluación de la docencia: perspectivas actuales. Barcelona: Paidós, 2000, p. 255-282.

SHULMAN, Lee S. Conocimiento y enseñanza: fundamentos de la nueva reforma. Revista de Currículum y Formación del Profesorado, v. 9, n. 2, p. 1-30, 2005. Disponível em: https://www.ugr.es/ recfpro/rev92ART1.pdf. Acesso em: 04 jun. 2018.

VERMERSCH, Pierre. Analyse de la tache et fonctionnement cognitif dans la programmation de l'enseignement. Bulletin de Psychologie, vol. XXXIII, 343, p. 1-13, 1977.Disponível em: https://www.grex2.com/assets/files/expliciter/Analyse_de_la_tache_et_cognitions-2.pdf. Acesso: 11 jun. 2018.

Recebido em: 26/08/2019.

Aprovado em: 14/11/2019. 